\title{
ALTRES LLIBRES REBUTS
}

AA. DD.

Conferencias culinarias, Tusquets Editores, Barcelona, 1982. Tusquets Editores, Barcelona, 1985.

WoOdy Allen,

No te bebas el agua, Tusquets Editotes, Barcelona, 1985.

YANN ANDRÉA, M. D. Marguerite Duras, Tusquets Editores, Barcelona, 1985.

Rafael Arjona,

El matarife,

Tusquets Editores, Barcelona, 1985. Tusquets Editores, Barcelona, 1982.

Ana Basualdo, Oldsmobile 1962,

Tusquets Editores, Barcelona, 1985. Tusquets Editores, Barcelona, 1985.

Georges Bataille, El azul del cielo,

Susana Constante,

La Creciente,

Tusquets Editores, Barcelona, 1982.

Álvaro Cunqueiro,

Fábulas y leyendas de la mar

(edición a cargo de Néstor Luján),

Tusquets Editores, Barcelona, 1982.

Antonio Gómez Rufo,

El último goliardo,

Milan Kundera,

La insoportable levedad del ser, 
«Papers»: Revista de Sociologia

EDWARD LEAR,

\section{Disparatario}

(edición a cargo de Cristóbal Serra y Tusquets Editores, Barcelona, 1984.

Eduardo Jordá),

Tusquets Editores, Barcelona, 1984.

Fran Lebowitz,

Breve manual de urbanidad,

Tusquets Editores, Barcelona, 1985.

ESTEBAN LÓPEZ,

Amor y tarot,

Tusquets Editores, Barcelona, 1982.

Hisako Matsubara,

Los pájaros del crepúsculo,

Tusquets Editores, Barcelona, 1985.

HUbert Monteilhet,

Neropolis,

Tusquets Editores, Barcelona, 1985.

Gilles Deleuze,

Spinoza: Filosofía práctica,

Marguerite Duras,

El viceconsul,

Tusquets Editores, Barcelona, 1986.

Paul Eluard,

Cartas a Gala, 1924-1948,

Tusquets Editores, Barcelona, 1986.

ANTONIO GARRIGUES WALKER,

La vuelta a Europa,

Promociones Publicaciones Universi-

tarias, Barcelona, 1986.

JoHN IRVING,

El mundo seguin Carp,

Tusquets Editores, Barcelona, 1986.
JoHN IRviNG,

El botel New Hampsbire,

La bestia rosa,

Tusquets Editores, Barcelona, 1986.

FAY Weldon,

Vida y amores de una maligna,

Tusquets Editores, Barcelona, 1985. Tusquets Editores, Barcelona, 1986.

SAMUEL BecketT,

Fin de partida,

Mateu Morro i Sebastia Serra, L'Esquerra Nacionalista a Mallorca,

Tusquets Editores, Barcelona, 1986. La Magrana, Barcelona, 1986.

Corneirus Castoriadis,

Ante la guerra,

Julio Ramón RIBEyRo,

Prosas apátridas,

Tusquets Editores, Barcelona, 1986. Tusquets Editores, Barcelona, 1986. 
Altres llibres rebuts

Fernando Valls Taberner, Estudios menores de Derecbo público y civil de Cataluña

(siglos XVIII, xIX y xx).

Vicente García Cervera, Las cartas de Saguia-el Hamra, Manuel Hidalgo, El pecador impecable, Tusquets Editores, Barcelona, 1986. Tusquets Editores, Barcelona, 1985. Tusquets Editores, Barcelona, 1986. 